\title{
High-performance liquid chromatography (HPLC): a rapid, flexible and sensitive method for separating islet proinsulin and insulin
}

\author{
P.A. Halban, C. J. Rhodes and S. E. Shoelson \\ E.P.Joslin Research Laboratories, Joslin Diabetes Center, Brigham and Women's Hospital, Harvard Medical School, Boston, Massachusetts, \\ USA
}

\begin{abstract}
Summary. Evaluating islet function in vitro involves studying both insulin biosynthesis and release. For the former, it is necessary to resolve insulin from its precursor, proinsulin. This has been achieved in the past by various procedures, each of which suffers from major drawbacks in terms of resolution and the time involved. We show here that reversed phase highperformance liquid chromatography (HPLC) outperforms previous methods for separating proinsulin from insulin in is-
\end{abstract}

let extracts without any prepurification or concentration steps. This HPLC method is rapid ( 90 min for a complete cycle, including washing the column) and reproducible, while allowing for unambiguous separation and quantification of proinsulin and insulin.

Key words: HPLC, proinsulin processing, insulin biosynthesis, isolated islets, islet function.
Insulin production by the pancreatic B cell consists of a number of individual biochemical events culminating in the release of secretory granule contents. In order to study insulin synthesis, it has become common practice to follow the incorporation of a radioactively labelled amino acid into insulin related peptides. Depending upon the timing of the experimental protocol and the nature of the tissue under investigation, however, radioactivity will be found in both the active hormone and its precursors. Since preproinsulin is converted to proinsulin rapidly, the major precursor form in the B cell is proinsulin. Evaluation of islet insulin biosynthesis must therefore rely upon a satisfactory method for separating proinsulin from insulin. Such separation was attempted in previous studies [1] by applying islet extracts to a Sephadex G-50 column. This method proved to be inadequate, however, due to poor separation of proinsulin and insulin and to co-elution of non-insulin related islet products. A modification of this method [2] involved immunopurification of proinsulin/insulin before chromatography, allowing for removal of the non-insulin-related contaminants but failing to improve the resolving power of the chromatographic step. An alternative method to column chromatography is polyacrylamide gel electrophoresis, which allows for excellent separation of proinsulin from insulin under most circumstances [3]. The weakness of the method for studying radioactively labelled products is that the specific radioactivity of the products must be high to allow for visualization of bands by fluorography within a useful time frame (i.e. an exposure time of less than 2 weeks).
Furthermore, it has become apparent that gel electrophoresis may not adequately resolve proinsulin from one of the two rat insulins [4].

Taking the above considerations into account, we have adapted an existing protocol for the resolution of insulin molecules by HPLC [5] for separating islet proinsulin and insulin. HPLC has been used previously by Noe et al. [6] for analyzing angler fish islet products, but their method involved prior gel chromatography and the use of a gradient which resolved the majority of islet peptides and was thus complicated to interpret. Our method is tailor-made for resolution of proinsulin and insulin to the exclusion of the majority of the other islet products, and requires no prior purification step.

\section{Materials and methods}

\section{Preparation of rat insulin and proinsulin standards}

Rat insulin and proinsulin were prepared by extracting rat pancreas with acid ethanol. To this end two pancreata from adult rats were minced in $10 \mathrm{ml}$ acid ethanol $(150: 47: 3 \mathrm{vol} / \mathrm{vol} / \mathrm{vol}$ absolute ethanol $-\mathrm{H}_{2} \mathrm{O}$ - concentrated hydrochloric acid $)$ and then sonicated $(2 \times 15 \mathrm{~s}$ Branson Sonifier). After leaving overnight at $2-4^{\circ} \mathrm{C}$ the extract was centrifuged and the supernatant decanted. The pellet was subjected to a further cycle of acid ethanol extraction as above. The pooled supernatants were then lyophylised. The dried material was dissolved in $1 \mathrm{ml}$ phosphate buffered saline (PBS) containing $1 \mathrm{mg} / \mathrm{ml}$ bovine serum albumin (BSA) and applied to a column (1 $\mathrm{cm}$ internal diameter, $80 \mathrm{~cm}$ length) containing Sephadex G-50 Fine (Pharmacia Inc., Piscataway, NJ, USA). The column was developed with PBS/BSA and fractions assayed for immunoreactive insulin. Immunoreactivity elut- 
ed in two peaks corresponding to proinsulin and insulin [1]. The leading edge of the proinsulin peak and the trailing edge of the insulin peak were considered to be enriched in these two products. After freeze-drying these fractions they were redissolved in $0.1 \mathrm{~mol} / 1$ hydrochloric acid and kept frozen for HPLC analysis.

Islet isolation. Rat islets were isolated from the pancreata of adult male $C D$ rats using a collagenase digestion method [7]. In brief, the method involved distention of the pancreas by injecting collagenase through the pancreatic duct, followed by dissection and incubation $\left(37^{\circ} \mathrm{C}\right)$. Islets were then separated from exocrine tissue using a discontinuous Ficoll gradient.

Islet incubations and pulse-chase protocol. Islets were maintained in tissue culture for $24 \mathrm{~h}$ to allow for recovery from the isolation procedure. They were then washed in a modified Krebs-Ringer bicarbonate buffer containing $10 \mathrm{mmol} / 1$ Hepes, $5 \mathrm{mg} / \mathrm{ml} \mathrm{BSA}, 8.3 \mathrm{mmol} / 1$ glucose (KRB-Hepes). The islets were then pulse-labelled with $\left[{ }^{3} \mathrm{H}\right]$ leucine ( $\mathrm{L}$ $\left[4,5-{ }^{3} \mathrm{H}\right]$ leucine, specific radioactivity $\left.141 \mathrm{Ci} / \mathrm{mmol}\right)$ for $5 \mathrm{~min}(1000$ islets in $0.2 \mathrm{ml} \mathrm{KRB-Hepes} \mathrm{containing} 0.2 \mathrm{mCi}\left[{ }^{3} \mathrm{H}\right]$ leucine and $16.7 \mathrm{mmol} / \mathrm{l}$ glucose). After washing with unlabelled KRB-Hepes, the islets were transferred to incubation vessels for the chase period of up to $180 \mathrm{~min}$ in KRB-Hepes, $2.8 \mathrm{mmol} / 1$ glucose. Batches of 25 islets were taken at set times either immediately after the pulse-label or during the chase period. The islets were washed twice in cold KRBHepes and then transferred to $1.5 \mathrm{ml}$ volume microfuge tubes in a final volume of $0.1 \mathrm{ml}$ PBS/BSA. The islets were sonicated $(2 \times 15 \mathrm{~s}$, Branson Sonifier, using a microprobe) and then centrifuged $(35,000 \mathrm{~g}$ $60 \mathrm{~min} .2-4^{\circ} \mathrm{C}$ ) to pellet membranous material. The supernatants were kept frozen for subsequent analysis.

HPLC. The HPLC system used was a Model 332 obtained from Beckman (Altex Division, San Ramon, Calif, USA) and consisted of a model 420 System Controller and two model 110B Solvent Delivery Modules (pumps) connected to an Altex Ultrasphere ODS $5 \mu \mathrm{m}$ column (length $25 \mathrm{~cm}$, internal diameter $4.6 \mathrm{~mm}$ ). Ultraviolet absorption was monitored at $213 \mathrm{~nm}$ using a Model LC-30 detector connected with a R50 pen recorder, both from Perkin Elmer, Norwalk, Conn, USA. The two buffers used were as follows: Buffer A (TEAP): Phosphoric acid, $50 \mathrm{mmol} / 1$; triethylamine $20 \mathrm{mmol} / 1$; sodium perchlorate, $50 \mathrm{mmol} / 1$; adjusted to $\mathrm{pH} 3.0$ with $\mathrm{NaOH}$. Buffer $\mathrm{B}\left(\mathrm{H}_{2} \mathrm{O}\right.$ / $A C N): 90 \%$ acetonitrile: $\left.10 \% \mathrm{H}_{2} \mathrm{O}\right)(\mathrm{v} / \mathrm{v})$. The flow rate was $1 \mathrm{ml} / \mathrm{min}$, and $1 \mathrm{~min}$ fractions were collected. Since small amounts of insulin were being eluted, and this peptide is known to be adsorbed to inert surfaces, each collecting tube contained $0.1 \mathrm{ml}$ of sodium borate $(0.5 \mathrm{mmol} / 1), 10 \mathrm{mg} / \mathrm{ml} \mathrm{BSA}$, adusted to $\mathrm{pH} 9.3$ with $\mathrm{NaOH}$. This served to provide BSA as a carrier protein and to neutralize the acidic element of the elution buffer (this is of importance if the samples are to be freeze-dried prior to immunoassay and also helps minimize chemiluminescence in samples destined for liquid scintillography). Radioactivity in samples was detected in a liquid scintillation counter after adding $10 \mathrm{ml}$ scintillant to each fraction. Immunoreactive insulin was measured after freeze-drying fractions and reconstituting in $0.5 \mathrm{ml}$ PBS/BSA using a conventional radioimmunoassay system with rat insulin (a generous gift of Dr. R. Chance, Eli Lilly Co., Indianapolis, Ind, USA) as the standard. Insulin reference standards were dissolved in HPLC elution buffer and then processed in the same way as the HPLC fractions to compensate for any interference in the assay system from nonvolatile components of the HPLC elution buffers.

\section{Results}

\section{Standardization of HPLC system}

A modification of the method of Shoelson et al. [5] was used to separate rat insulin and proinsulin. HPLC is an ideal tool for separating closely related insulin molecules [5] and could thus certainly be expected to resolve

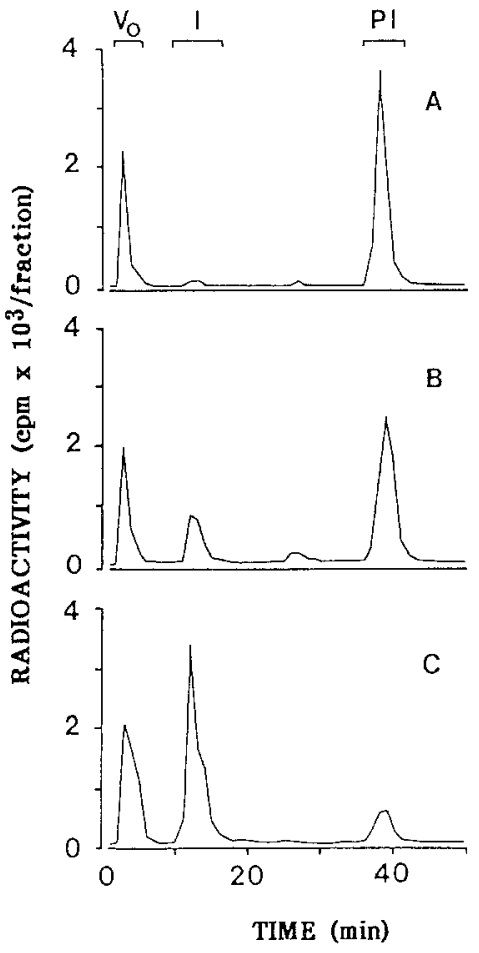

Figure 1. Profiles of radioactive material eluting from HPLC: rat islets were pulse-labelled for $5 \mathrm{~min}$ and then incubated for A 30-, B 60 or $\mathbf{C} 120$-min chase. Extracts of islets were then analyzed by HPLC as described in Results. The elution times for rat proinsulin (PI) and insulin (I) are shown (VO = void volume)

the two rat proinsulin gene products (i.e. proinsulin I and II and insulin I and II); this was not, however, the intention for the initial series of studies. Indeed, it was anticipated that resolution of proinsulin I and II, insulin I and II and the related conversion intermediate molecules would have prevented unambiguous interpretation of elution profiles. A system was therefore conceived in which both insulin I and II on the one hand, and proinsulin I and II on the other, eluted as single well separated peaks. The semipurified rat proinsulin and insulin standards (see Methods) were used for standardization. Fractions eluting from the column were monitored for immunoreactivity using an anti-insulin serum which cross-reacts with rat proinsulin. The total immunoreactivity applied to the column was always compared with that eluting and found to correspond to a recovery of $90-110 \%$.

Rat insulins were eluted using an isocratic system of $36 \%$ Buffer B. Both of the rat insulins eluted between 12 and $13 \mathrm{~min}$. At $20 \mathrm{~min}$ after sample injection, the $\% \mathrm{~B}$ was increased linearly from 36 to $39 \%$ over a 15 -min period and maintained at $39 \%$ for an additional $25 \mathrm{~min}$, allowing for isocratic elution of the rat proinsulins. Once the proinsulins had eluted, the column was washed by raising the organic phase (Buffer B) to $60 \%$; the system was then returned to initial conditions $(36 \% \mathrm{~B})$. An entire cycle (from sample injection to complete washing and reequilibration of the column) could be accomplished in $90 \mathrm{~min}$. 
Table 1. A comparison of analyses of islet extracts by immunoprecipitation and by HPLC following a 5-min pulse-label ( $\left.\left[{ }^{3} \mathrm{H}\right] \mathrm{leucine}\right)$ and up to $180 \mathrm{~min}$ of a chase incubation.

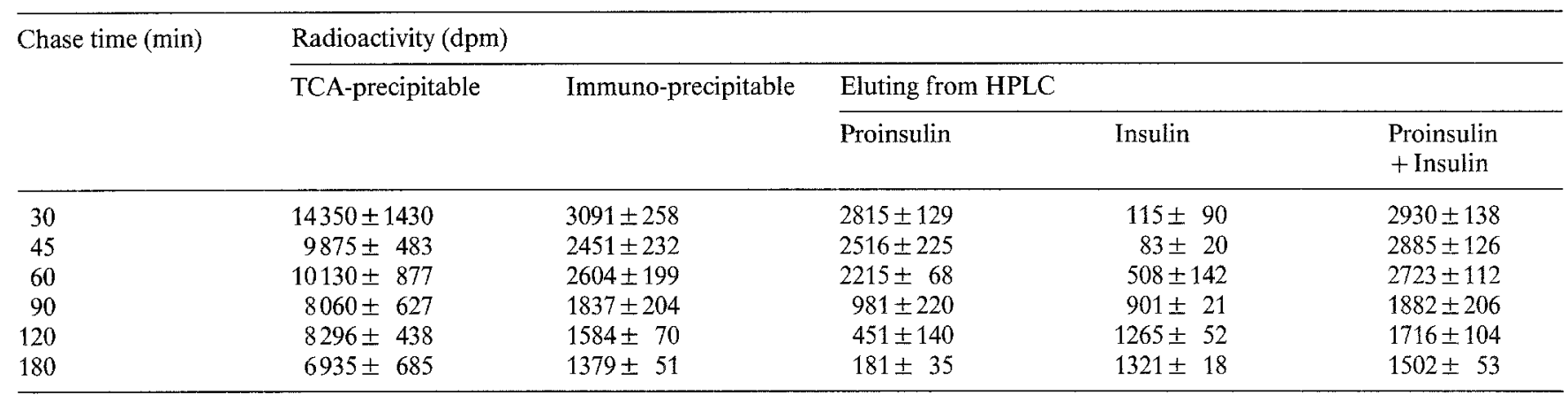

Data are expressed as mean \pm SEM for three independent pulse-chase experiments. All samples contained 100 ng immunoreactive insulin. TCA: trichloroacetic acid

Table 2. Reproducibility of HPLC separation of rat proinsulin and insulin

\begin{tabular}{|c|c|c|c|c|c|}
\hline \multirow{2}{*}{$\begin{array}{l}\text { HPLC } \\
\text { run }\end{array}$} & \multicolumn{2}{|c|}{ Elution time (min) } & \multicolumn{2}{|c|}{ Radioactivity (dpm) } & \multirow{2}{*}{$\begin{array}{l}\text { Proinsulin } \\
\text { conversion } \\
(\%)\end{array}$} \\
\hline & $\begin{array}{l}\text { Proinsulin } \\
\text { peak }\end{array}$ & $\begin{array}{l}\text { Insulin } \\
\text { peak }\end{array}$ & Proinsulin & Insulin & \\
\hline 1 & 39 & 12 & 3750 & 2783 & 57.6 \\
\hline 2 & 40 & 13 & 3306 & 2719 & 58.1 \\
\hline 3 & 39 & 12 & 3955 & 3040 & 58.5 \\
\hline 4 & 40 & 13 & 3887 & 2940 & 60.1 \\
\hline $\begin{array}{l}\text { Mean } \pm \\
\text { SEM }\end{array}$ & $39.5 \pm 0.3$ & $12.5 \pm 0.3$ & $3725 \pm 145$ & $2871 \pm 73$ & $58.6 \pm 0.5$ \\
\hline
\end{tabular}

Rat islets were pulse-labelled $\left(5 \mathrm{~min},\left[{ }^{3} \mathrm{H}\right]\right.$ leucine) and then incubated without label for $90 \mathrm{~min}$ (chase). After sonication, four replicate samples were analysed successively by HPLC. The extent of conversion of proinsulin to insulin takes into account the loss of leucine residues associated with C-peptide [2]

\section{Validation and quantification of HPLC system using islet extracts}

Isolated rat islets were pulse-labelled with $\left[{ }^{3} \mathrm{H}\right]$ leucine for $5 \mathrm{~min}$ and then subjected to a 3 -h chase incubation in the absence of label. At set times during the chase period, islets were taken, washed and then sonicated in PBS/BSA to extract proinsulin and insulin. Representative elution profiles for $10-20 \mu \mathrm{l}$ volume aliquots containing $100 \mathrm{ng}$ total immunoreactive insulin are shown in Figure 1. The two peaks eluting at 12 and $39 \mathrm{~min}$ corresponded in time to rat insulin and proinsulin respectively. To confirm the identity of this material, aliquots of islet extracts were first immunoprecipitated using a large excess of anti-insulin serum under conditions previously shown to quantitively precipitate both insulin and proinsulin $[1,2]$. The precipitated products were then applied to HPLC; the only major radioactive peaks observed were at 12 and $39 \mathrm{~min}$. The total radioactivity eluting with each peak was, furthermore, comparable to that seen in the nonpurified sample, indicating that the peaks contained only proinsulin or insulin. When nonimmune serum was used in place of anti-insulin serum, there was no enrichment of these two peaks. Based upon these observations, as well as the immunoreactivity in these peaks, it is concluded that they do indeed represent the hormone and prohormone respectively.

During the course of the chase period, radioactivity was found to decrease in the proinsulin peak and to increase in the insulin peak (Fig. 1) in keeping with proinsulin to insulin conversion. In order to determine whether there was quantitative recovery of both proinsulin and insulin from the HPLC system, results of HPLC and of quantitative immunoprecipitation of aliquots of the same samples were compared (Table 1). Immunoprecipitable radioactivity consists of both proinsulin and insulin. These values should therefore be compared to those of combined radioactivity of proinsulin and insulin eluting from HPLC. Throughout the chase period it can be seen that results using the two methods are essentially identical. It should be noted that the radioactivity associated with proinsulin and insulin decreased with time. This is because some of this material is released from islets during the chase. It can also be seen that proinsulin and insulin only account for approximately $20 \%$ of the total sample radioactivity. The remaining radioactivity is accounted for by $\left[{ }^{3} \mathrm{H}\right]$ leucine itself and by non-insulin related proteins synthesized within islets during the 5-min chase period. Such products were found to elute from the HPLC column during the washing cycle at high acetonitrile levels and have not been characterized.

In order to assess the reproducibility of the HPLC system, aliquots of an islet extract (90-min chase) were subjected to repeated analysis. The results are shown in Table 2. It is apparent that the peak elution times for proinsulin and insulin and the recovery of radioactivity in the two peaks is remarkably consistent from one run to the next.

\section{Separation of rat insulins I and II}

In order to separate the two rat insulins, islet extracts were eluted isocratically at $35 \%$ Buffer solvent B. Rat insulin I eluted between 31 and $34 \mathrm{~min}$ and rat insulin II between 39 and $43 \mathrm{~min}$. The two insulin molecules were 
identified by the following criteria: (1) their known behavior on HPLC [8]; (2) the appearance of two distinct peaks of insulin immunoreactivity; and (3) the presence of leucine in both products and that of methionine in only rat insulin II.

Separation of rat insulins I and II from each other and from rat proinsulin can be readily accomplished in one chromatographic run by combining the two described methods (i.e. isocratic elution of insulins I and II at $35 \%$ solvent B over 45 min followed by an increase to $39 \% \mathrm{~B}$ for elution of proinsulin). Greater resolution is gained at the price of increased cycle time. Attempts to resolve rat proinsulins I and II utilizing modifications of the described procedures have thus far been unsuccessful.

\section{Discussion}

HPLC has been shown by others to be the method of choice for the separation of insulin and related peptides [8]. For an analytical method to be useful for research purposes, however, it should fulfill certain stringent requirements; it must, at the least, be (1) accurate, (2) reproducible, (3) quantitative and (4) practical. We have shown that our method for HPLC analysis of rat islet extracts fulfills all of these requirements. It should, furthermore, be stressed that the materials analysed were not subject to any prior purification step such as immunoprecipitation or gel chromatography. Despite the injection of crude islet extracts directly onto the HPLC column, we have yet to find any detrimental effect to the column. It must be assumed that the washout cycle used between analytical runs is sufficient to displace potentially contaminating products from the column.

Complete conversion of proinsulin to insulin involves both endopeptidase-like (cleavage at dibasic residues) and exopeptidase-like (basic residues are absent from the $\mathrm{N}$-terminus of insulin's A-chain and the $\mathrm{C}$ terminus of the B-chain) activities. Although conversion can be modeled by incubating proinsulin with trypsin and carboxypeptidase B, the actual converting enzyme(s) has yet to be characterized. Intermediate products of conversion (C-peptide remaining attached at either the A-C or B-C junctions) can be found in the pancreas and circulation of humans and can be resolved by HPLC [9].

No standards are available for characterization of the elution patterns of rat proinsulin intermediate products. Based upon the data from studies on human material [9] and on preliminary results using beef proinsulin conversion intermediates (data not shown), we expect these products to elute between insulin and proinsulin. Although distinct radioactive peaks were found eluting at the appropriate times from the HPLC column after injection of rat islet extracts, and these products were, additionally, immunoprecipitable, it is not yet possible to identify these products unambiguously. Similarly, Cpeptide, although predicted to elute shortly before insulin, has not been identified. It is to be expected, however, that the system as described, or with only minor modifications, will prove suitable for the quantification and characterization of all intermediates and by-products of proinsulin conversion.

Acknowledgements. We are greatly indebted to Eli Lilly and Co., Indianapolis, Ind, USA, for their generous gift of the HPLC system used for this study, and to Dr. B. Frank of that company, for his help in setting up the procedure and for many useful discussions. We also thank Mr. R.Mutkoski for expert technical assistance and Ms. Z. Murrish for typing the manuscript. This work was supported by the National Institutes of Health (AM35292, AM31036 and BRSG-507-RR-05673) and by a grant from the Greenwall Foundation, New York.

\section{References}

1. Halban PA, Wollheim CB, Blondel B, Niesor E, Renold AE (1979) Perturbation of hormone storage and release induced by cyproheptadine in rat pancreatic islets in vitro. Endocrinology 104: 1096-1106

2. Halban PA (1982) Inhibition of proinsulin to insulin conversion in rat islets using arginine and lysine analogs: lack of effect on rate of release of modified products. J Biol Chem 257: 13177-13180

3. Clark JL, Steiner DF (1969) Insulin biosynthesis in the rat: demonstration of two proinsulins. Proc Natl Acad Sci USA 62: 278-285

4. Kakita K, O'Connell K, Permutt MA (1982) Pancreatic content of insulins I and II in laboratory rodents: analysis by immunoelectrophoresis. Diabetes 31: $841-845$

5. Shoelson S, Hareda M, Blix P, Nanjo A, Sanke T, Inouye K, Steiner D, Rubenstein A, Tager H (1983) Three mutant insulins in man. Nature 302: 540-543

6. Noe BD, Debo G, Spiess J (1984) Comparison of prohormone-processing activities in islet microsomes and secretory granules: evidence for distinct converting enzymes for separate islet prosomatostatins. J Cell Biol 99: 578-587

7. Gotoh M, Maki T, Halban P, Mutkoski R, Satomi S, Monaco A (1985) Reproducibly high yield of rat islets by stationary digestion after indraductal collagenase injection. Diabetes 34 [Supp 1 1]: 169A (Abstract)

8. Rivier J, McClintock R (1983) Reversed-phase high performance liquid chromatography of insulins from different species. J Chromatography 268:112-119

9. Given BD, Cohen RM, Shoelson SE, Frank BH, Rubenstein AH, Tager HS (1985) Biochemical and clinical implications of proinsulin conversion intermediates. J Clin Invest 76:1398-1405

Received: 29 July 1986

and in revised form: 28 October 1986

Dr. Philippe A. Halban

E.P. Joslin Research Laboratory

Joslin Diabetes Center

One Joslin Place

Boston, MA 02215

USA 